\title{
Special effects of parsley (Petroselinum crispum) on streptozotocin-induced diabetic rats: biochemical profiles.
}

\author{
Mohamed Sabry Abd elbaky', Tahsin Shoala², Mohamed Hamdy Abdelwahab ${ }^{3}$ \\ ${ }^{1}$ Head of the Department of Nutrition and Food Sciences, Faculty of Home Economics, \\ Helwan University. \\ ${ }^{2}$ Envirobmental Biotechnology Department, College of Biotechnology, Misr University for \\ Science and Technology, Egypt. \\ ${ }^{3}$ Dietitians at Children's Cancer Hospital Egypt-57357.
}

\begin{abstract}
This study was conducted to evaluate the effect of Parsley (Petroselinum crispum) on some biochemical profiles streptozotocin-induced diabetic rats. For this purpose, 20 male albino rats were divided into 4 groups according to the program assigned 5 rats per group: Group 1: control group kept on basal ration, Group 2: Parsley group kept on basal ration + Parsley $2 \mathrm{gm} / \mathrm{kg}$ body weight, Group 3: Diabetic group rats injected intra peritoneal with STZ $45 \mathrm{mg} / \mathrm{kg}$ body weight and kept on basal diet, Group 4: Diabetic + Parsley rats injected intra peritoneal with STZ $45 \mathrm{mg} / \mathrm{kg}$ body weight and kept on basal diet + Parsley $2 \mathrm{gm} / \mathrm{kg}$ body weight. Results showed that, treatment of the STZ induced diabetic rats with parsley, resulted in significant decrease in fasting blood glucose and glycated hemoglobin compared to control group and there is significant difference within all groups in ALT, AST, Urea and Creatinine also in Total cholesterol and Triglyceride. In summary, the best results of biochemical profiles in diabetic rats occurred on, diabetic + Parsley rats injected intra peritoneal with STZ 45mg/kg body weight and kept on basal diet + Parsley $2 \mathrm{gm} / \mathrm{kg}$ body weight. Henceforth, a clinical could be conducted before general recommendation.
\end{abstract}

Key words: Diabetes mellitus, blood glucose, Streptozotocin, Parsley 


\section{INTRODUCTION}

Diabetes, often referred by doctors as diabetes mellitus, describes a group of metabolic diseases in which the person has high blood glucose (blood sugar), either because insulin production is inadequate, or because the body's cells do not respond properly to insulin, or both (Davis et al., 2005). Patients with high blood sugar experience polyuria (frequent urination); they become increasingly thirsty (polydipsia) and hungry (polyphagia) (Bell, 2003). The most common types are: Type 1 diabetes (IDDM) where the body's immune system attacks and destroys the cells that produce insulin and type 2 diabetes (NIDDM), where the body doesn't produce enough insulin, or the body's cells don't react to insulin. However, type 2 diabetes is widely spread than type1 (WHO, 2013). Diabetes increases risk for many serious health problems over the long-term complications developed gradually due to hyperglycemia microenvironment in both types of diabetes damage, dysfunction and failure of multiple organs (Olsen et al., 2004).

Parsley is a popular culinary and medicinal herb recognized as one of the Functional foods for its unique antioxidants, and disease preventing properties. This wonderful, fragrant rich biennial herb is native to the Mediterranean region belongs to the Apiaceae family, in the genus; Petroselinum. Its botanical name is Petroselinum crispum (Mozafarian, 2007). Also, its phytochemical constituents are flavonoids, carbohydrates, essential oil components, coumarin (Chaves et al., 2011). Parsley plants have wide range of pharmacological activities of including antioxidant, hepatoprotective, brain protective, antidiabetic (Ziyyat, 1997), analgesic, spasmolytic, immunosuppressant, antiplatelet, gastro protective, cytoprotective, laxative, estrogenic, diuretic (Rehecho et al., 2011). Also, hypoglycemic constituents in parsley plants which are used in folklore medicine to treat diabetes mellitus (El-Aboudi and Afifi, 2010). 
Therefore, the main aim of our current study focused on testing the efficacy of parsley on improvement of blood glucose level on streptozotocin-induced diabetic rats.

\section{MATERIAL AND METHODS}

\section{Plant Material and Extraction Procedure}

Parsley leaves were collected from Egypt local market carefully washed with tap water and left to dry for 1 week in the shade at room temperature. Then they were stored in well-sealed cellophane bags. The air-dried leaves of the plant were milled into fine powder in a Waring commercial blender. Dried parsley leaves $(100 \mathrm{~g})$ were extracted by adding $1000 \mathrm{ml}$ of distilled water and boiling for $30 \mathrm{~min}$. Then the extract was filtered and the filtrate evaporated to dryness under reduced pressure using a rotary evaporator, the extract yield was $31.57 \%$ w/w in this research as cited by (Refiye et al., 2003).

\section{Rats and treatments}

Forty albino male rats, weighting 150- $200 \mathrm{~g}$ and of average age 2 months, purchased from health institute were used. The experiment was conducted according to the ethical norm approved by Institutional Animal Ethics Committee (IAEC). The rats were left in clean and disinfectant cages (5 rate/ cage). Rats in all groups were provided with food (based diet) and water was available adlibtum. They were given basal diet before experiment for acclimatization and to ensure normal growth of rats at the end of experimental period 30 days.

\section{Chemicals and reagents}

\section{Experimental design and sampling}

Twenty male rats were divided equally into four groups each group contains 5 rats as follow: Group 1: control group kept on basal diet for 30 days, Group 2: 
Parsley group kept on basal diet + Parsley $2 \mathrm{gm} / \mathrm{kg}$ body weight by gavage (Tunalı et al., 1999) for 30 days, Group 3: Diabetic group rats injected intra peritoneal with STZ $45 \mathrm{mg} / \mathrm{kg}$ body weight and kept on basal diet, Group 4: Diabetic + Parsley rats injected intra peritoneal with STZ $45 \mathrm{mg} / \mathrm{kg}$ body weight and kept on basal diet + Parsley $2 \mathrm{gm} / \mathrm{kg}$ body weight by gavage. The treatment was given for one month after that the rats were fasted overnight, anaesthetized using di-ethyl ether and the blood samples collected from canthus of eye using hematocrit tubes then immediately after euthanized, the rats were dissected and the livers were collected, washed with ice cold saline and stored at -18 Celsius for biochemical measurement.

\section{Serum biochemical analysis}

The serum concentrations of blood glucose (Kaplan 1984), serum total cholesterol level (Deeg and Zeigenohrn, 1983), serum triglyceride level Fossati and Prencipe (1982), blood urea concentration (Tabacco et al., 1979), serum creatinine concentration (Henry, 1984), serum alanine transaminase (Reitman and Frankel, 1957), serum aspartate transaminase (Reitman and Frankel, 1957).

\section{RESULTS}

The data presented in table (1) showed that, there is significant difference in blood glucose level between the group given parsley extract and the intact control group (Fig 1). While, injection of STZ, resulted in significant increase in blood glucose level. The data summarized in table (2) revealed that, STZ injection caused significant increase in serum Ch and TG level (Fig 2). The data presented in table (3), showed that there is no significantly differs in AST, ALT from parsley group compared to control one (Fig 3). Also, the injection of STZ resulted in significant increase in AST, ALT. While treatment of STZ-induced diabetic rats with parsley significantly 
decreased ALT compared to control diabetic group. However, AST does not significantly change in STZ injected group fed with parsley compared with diabetic control group. The data summarized in Table (4) revealed that, the injection of STZ resulted in significant increase in serum urea level and serum creatinine level (Fig 4). While treatment of STZ-induced diabetic rats with parsley significantly decreased serum creatinine level compared to control diabetic group. However, serum urea level does not significantly change in STZ injected group fed with parsley compared with diabetic control group.

Table 1. Effect of parsley on Diabetic profile in STZ-induced diabetic rats compared to control.

\begin{tabular}{|c|c|}
\hline \multirow{2}{*}{ Group } & Parameter \\
\cline { 2 - 2 } Control & Glucose $(\mathbf{m g} / \mathbf{d L})$ \\
\hline Parsley & $85.58 \pm 0.82^{\mathrm{b}}$ \\
\hline Diabetic & $74.45 \pm 0.56^{\mathrm{b}}$ \\
\hline Diabetic + Parsley & $355.40 \pm 0.87^{\mathrm{a}}$ \\
\hline
\end{tabular}

Values are Means \pm SEM. Means without a common superscript in a column differ significantly $(\mathrm{P}<0.05)$. a significantly of control $\mathrm{P}<0.05$. b significantly of Diabetic $\mathrm{P}<0.05$.

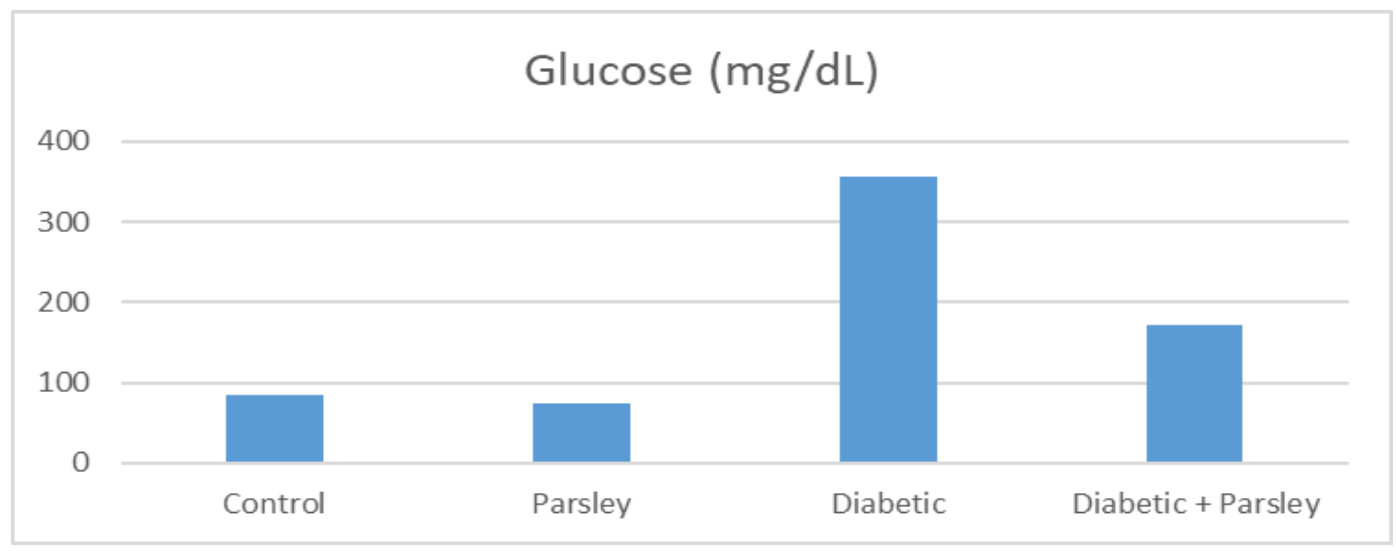

Fig 1. Impacts of parsley on diabetic profile in in STZ-induced diabetic rats compared to control. 
Table 2. Influence of parsley on lipid profile in STZ-induced diabetic rats compared to control.

\begin{tabular}{|c|c|c|}
\hline \multirow[b]{2}{*}{ Group } & \multicolumn{2}{|c|}{ Parameters } \\
\hline & Total cholesterol (mg/dl) & Triglycerides (mg/dl) \\
\hline Control & $113.32 \pm 0.32^{b}$ & $129.43 \pm 0.70^{b}$ \\
\hline Parsley & $107.61 \pm 0.85^{b}$ & $125.39 \pm 0.67^{b}$ \\
\hline Diabetic & $130.85 \pm 1.41^{\mathrm{a}, \mathrm{b}}$ & $264.49 \pm 1.87^{\mathrm{a}}$ \\
\hline Diabetic + Parsley & $124.25 \pm 0.55^{\mathrm{a}}$ & $128.97 \pm 0.92^{b}$ \\
\hline
\end{tabular}

Values are Means \pm SEM. Means without a common superscript in a column differ significantly $(\mathrm{P}<0.05)$. a significantly of control $\mathrm{P}<0.05$. b significantly of Diabetic $\mathrm{P}<0.05$.

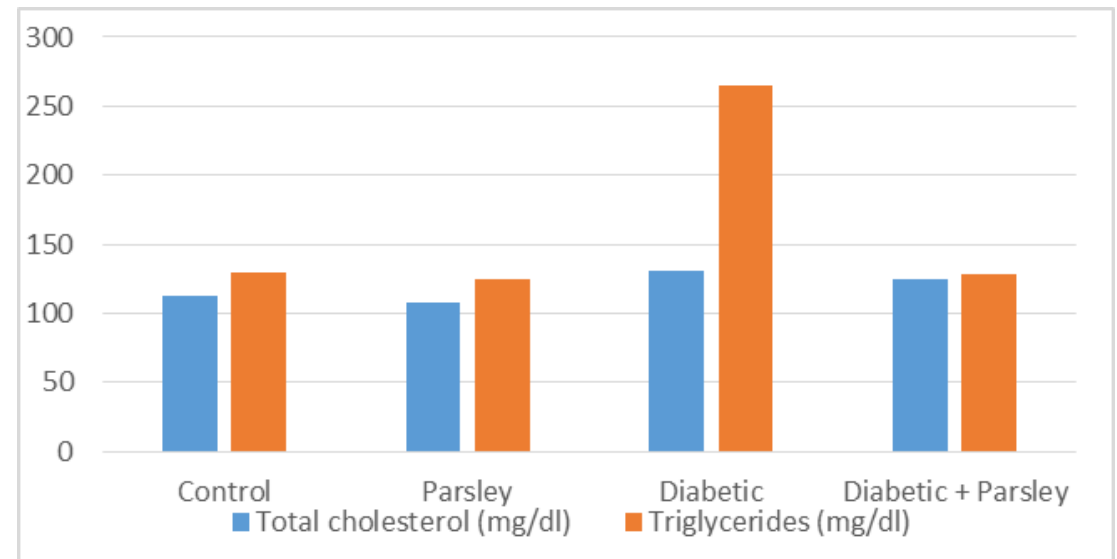

Fig 2. Effect of parsley on lipid profile in STZ-induced diabetic rats compared to control.

Table 3. Effect of parsley on liver function test in STZ-induced diabetic rats compared to control.

\begin{tabular}{|c|c|c|}
\hline \multirow{2}{*}{ Group } & \multicolumn{2}{|c|}{ Parameters } \\
\cline { 2 - 3 } & $\begin{array}{c}\text { AST } \\
(\mathrm{mg} / \mathrm{dL})\end{array}$ & $\begin{array}{c}\text { ALT } \\
(\mathrm{mg} / \mathrm{dL})\end{array}$ \\
\hline Control & $85.4 \pm 0.79^{\mathrm{b}}$ & $38 \pm 0.45^{\mathrm{b}}$ \\
\hline Parsley & $76.8 \pm 1.05^{\mathrm{b}}$ & $37.2 \pm 0.52^{\mathrm{b}}$ \\
\hline Diabetic & $136.8 \pm 1.44^{\mathrm{a}}$ & $82.2 \pm 0.26^{\mathrm{a}}$ \\
\hline Diabetic + Parsley & $138.2 \pm 1.52^{\mathrm{a}}$ & $41.6 \pm 0.91^{\mathrm{b}}$ \\
\hline
\end{tabular}

Values are Means \pm SEM. Means without a common superscript in a column differ significantly $(\mathrm{P}<0.05)$. a significantly of control $\mathrm{P}<0.05$. b significantly of Diabetic $\mathrm{P}<0.05$. 


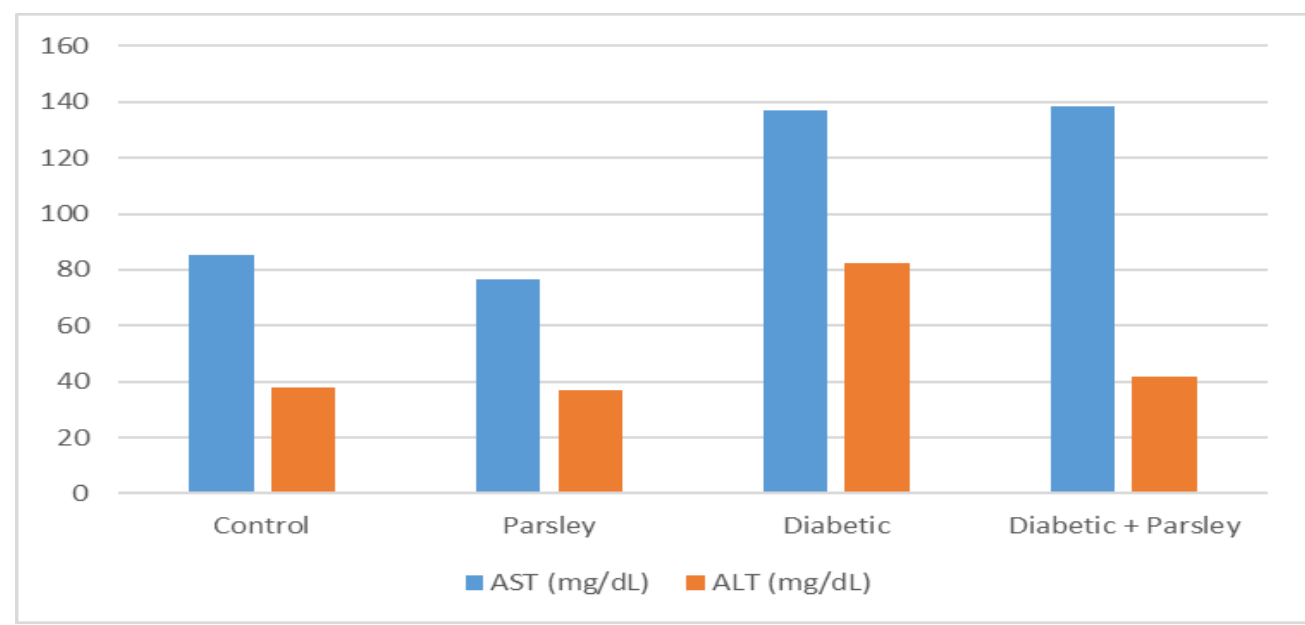

Fig 3. Outcome of parsley on liver function test in STZ-induced diabetic rats compared to control.

Table 4. Impact of Parsley on kidney function test in STZ-induced diabetic rats compared to control.

\begin{tabular}{|c|l|l|}
\hline \multirow{2}{*}{ Group } & \multicolumn{2}{|c|}{ Parameters } \\
\cline { 2 - 3 } & \multicolumn{1}{|c|}{ Urea $(\mathbf{m g} / \mathbf{d l})$} & \multicolumn{1}{c|}{$\begin{array}{c}\text { Creatinine } \\
(\mathbf{m g} / \mathbf{d l})\end{array}$} \\
\hline Control & $2.54 \pm 0.05^{\mathrm{b}}$ & $1.5 \pm 0.03^{\mathrm{b}}$ \\
\hline Parsley & $2.19 \pm 0.02^{\mathrm{b}}$ & $1.34 \pm 0.02^{\mathrm{a}, \mathrm{b}}$ \\
\hline Diabetic & $3.57 \pm 0.10^{\mathrm{a}}$ & $1.98 \pm 0.06^{\mathrm{a}}$ \\
\hline Diabetic +Parsley & $2.66 \pm 0.02$ & $0.4 \pm 0.01^{\mathrm{b}}$ \\
\hline
\end{tabular}

Values are Means \pm SEM. Means without a common superscript in a column differ significantly $(\mathrm{P}<0.05)$. a significantly of control $\mathrm{P}<0.05$. b significantly of Diabetic $\mathrm{P}<0.05$.

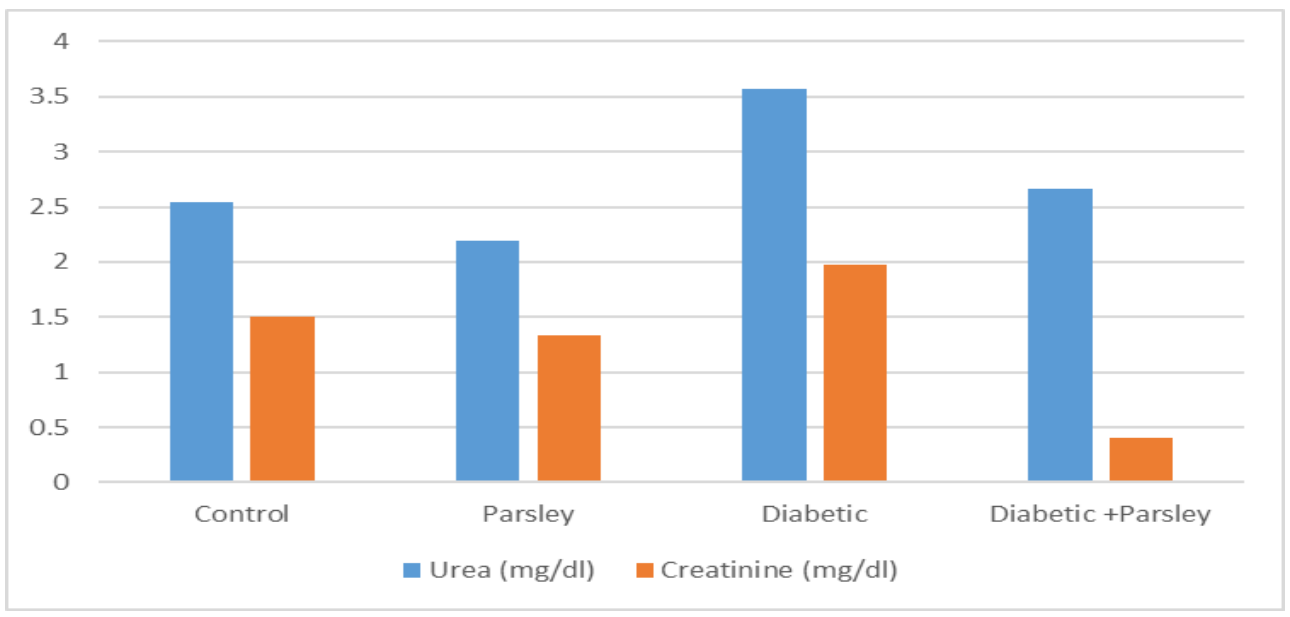

Fig 4. Effect of Parsley on kidney function test in STZ-induced diabetic rats compared to control. 


\section{DISCUSSION}

Diabetes mellitus (DM) is one of the metabolic disorders in which there are high glucose levels over a long interval of time (WHO, 2013). DM has anomalous insulin discharge, activity, or both. With imbalance in carbohydrate, lipid, and protein digestion and is characterized by the presence of hyperglycemia (Bell, 2003). Furthermore, DM is a significant global medical burden; the metabolic problems are a primer for developing illnesses, like nephropathy, retinopathy, neuropathy, and cardiovascular illnesses (Bate and Jerums, 2003). STZ is a compound regularly utilized for eliciting diabetes in test rodents; STZ causes diabetes by aggressive exhaustion of b-cells, which prompts a decrease in insulin release. It is known that parsley produces hypoglycemia, these natural products should help control glucose levels, lower insulin resistance, and inhibit diabetes-related co-morbidities (Ziyyat, 1997).

The data presented in table (1), showed that there is insignificant difference in fasting blood glucose between the group given parsley extract and the intact control group (Fig 1). While the injection of STZ resulted in significant increase in fasting blood glucose this come parallel to what cited by (Sajad et al., 2008) who reported that, significant increase in blood glucose concentrations were recorded in STZ induced diabetic rabbits compared to control rabbits, the same authors cited that the elevation in blood glucose concentrations reflect abnormalities in beta cell function induced by STZ. The data summarized in Table (2) revealed that, STZ injection caused insignificant increase in serum $\mathrm{Ch}$ and TG. These results come in agreement with those obtained by (Cathrine et al., 1991) who reported that, a significant increase in serum Ch, TG and as well as liver $\mathrm{Ch}$ were increase in alloxan induced diabetic rabbits compared to control rabbits (Fig 2). The data summarized in Table (3) revealed that, STZ injection caused insignificant increase in serum ALT and AST. These results 
were consistent with the results of the scientist (Bolkent et al., 2004) Furthermore, the results of the study conducted by this scientist (Sawsan 2017) were also consistent with those of this study (Fig 3). The only difference was that the rats in the first study were pregnant. The data summarized in Table (4) revealed that, the injection of STZ resulted in significant increase in serum urea and creatinine level (Fig 4). These results come in agreement with those obtained by (Sajad et al., 2008) Who showed that, a significant increase in blood urea and serum creatinine were recorded in STZ induced diabetic rabbits compared to control rabbits. 


\section{REFERENCES}

Bate, K.L., Jerums, G. 2003. Preventing complications of diabetes. Med J Australia, 179, 498-503.

Bell, D.S. 2003. Diabetic cardio myopathy. Diabetes care. 26: 2949-2951.

Catherine, M. L., Aram, V. C., Peter, B., Vassilis, I. Z. 1991. Effect of dietary cholesterol and alloxan-diabetes on tissue cholesterol and apolipoprotein E mRNA levels in rabbit. J. of Lipid Res., 32: 431-438.

Chaves, D. S., Frattani, F. S., Assafim, M. 2011. Phenolic chemical composition of Petroselinum crispum extract and its effect on haemostasis. Nat Prod Commun 6(7): 961-964.

Davis, T.M., Bruce, D.G., Davis, W.A. 2005. Predictors of first stroke in type 1 diabetes: The Fremantle Diabetes Study. Diabet. Med., 22: 551-553.

Deeg, R., Zeigenohrn, J. 1983. kinetic enzymatic method for automated determination of total cholesterol in serum. J. Clin. Chem., 29(10): 1798-1802

El-Aboudi, A., Afifi, F. U. 2011. Plants used for the treatment of diabetes in Jordan. Pharmaceutical biology; (49): 221-239.

Fossati, P., Prencipe, L. 1982. Serum triglycerides determined calorimetrically with an enzyme that produces hydrogen peroxide. Clin. Chem., 28(1): 20772080 .

Friedwald, W. T. 1972. Estimation of the concentration of low-density lipoprotein cholesterol in plasma without use of the preparative ultracentrifuge. Clin. Chem., 18:499-502. 
Henry, J.B. 1984. Clinical diagnosis and management 17th edition, Saunder Publisher. Cited in Biosystems Pamphlet.

Kaplan, L.A. 1984. Glucose. Clin. Chem. The C. V. Mosby Co. St Louis. Toronto. Princeton, $1032-1036$.

Montgomery, H.A.C., Dymock, J. 1961. The determination of nitrite in water. Analyst, 86, 414-416.

Mozafarian, V. 2007. Flora of Iran. Tehran: Forest \& Ranglands Research Institute Press: 54.

Olsen, B. S., Sjolie, A. k. Hougard, P., Johannesen, J., Marinelli, K., Jacobsen, B. B., Mortensen, H. B. 2004. The Danish Study Group of Diabetes in Childhood. The significance of the prepubertal diabetes duration for the development of retinopathy and nephropathy in patients with type 1 diabetes. J. Diabet. Comp., 18 (3): 160-164.

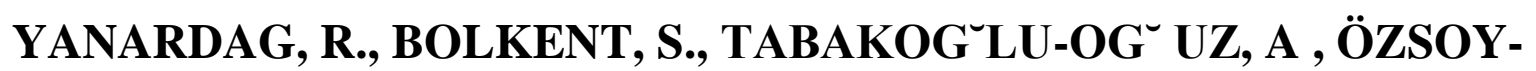
SAÇAN, Ö. 2003. Effects of Petroselinum crispum Extract on Pancreatic B Cells and Blood Glucose of Streptozotocin- Induced Diabetic Rats. Biol. Pharm. Bull. 26 (8) 1206- 1210.

Rehecho, S. Uriarte-Pueyo, I., Calvo, J., Vivas, L.A. 2011. Ethnopharmacological survey of medicinal plants in Nor-Yauyos, a part of the Landscape Reserve Nor- Yauyos-Cochas, Peru. J Ethnopharmacol; 133(1): 75-85.

Bolkent, R. Yanardag, O. Ozsoy-Sacan, Karabulut-Bulan, O. 2004. Effects of Parsley (Petroselinum crispum) on the Liver of Diabetic Rats: a Morphological and Biochemical Study IN PHYTOTHERAPY RESEARCH. Phytother. Res. 18, 996-999. 
Sajad, H. M., Abdul, B., Bhagat, R.C., Darzi, M. M., Abdul,W. S. 2008. Biochemical and Histomorphological Study of Streptozotocin-Induced Diabetes Mellitus in Rabbits. Pakistan J. of Nutr., 7(2):359-364.

El-Shamy, S. A. 2017. Ameliorative Effect of Parsley Extract on Some Diabetes Complications in the Pregnant Rats in Researcher; 9(12).

Tabacco, A.; Meiathini, F.; Moda, E. and Tarli, P. 1979. Simplified enzymatic/colorimetric serum urea nitrogen determination. Clin Chem. 25: 336-337.

Tunalı, T., Yarat, A., Yanardag, R., Özçelik, F., Özsoy, Ö., Ergenekon, G., Emekli, N. 1999. Phytother. Res., 13, 138-141.

WHO. World Health Organization 2013. Diabetes Fact sheet N312.

Ziyyat, A., Legssyer, A., Mekhfi, H. 1997. Phytotherapy of hypertension and diabetes in oriental Morocco. J. Ethnopharmacol; 58(1): 45-54. 